Volume 2, Issue 1, pages 59-66

\title{
Comparison Simulation Analysis of the Gradual Summation of a Function with Recognition of Direct Extrapolation via IN Series
}

\author{
Stephanus Ivan Goenawan \\ Department of Industrial Engineering, Atma Jaya Catholic University, \\ Cisauk BSD Highway, Tangerang, Indonesia \\ Corresponding Author: steph.goenawan@atmajaya.ac.id
}

(Received 26-06-2019; Revised 05-08-2019; Accepted 05-08-2019)

\begin{abstract}
A set of data pattern that have the characteristic of a function can be approached using Newton series simulation. When using the Newton series, the simulation result of the summation of extrapolation data can be gradually done in step by step. However, if using the IN series, the simulation result of the summation of extrapolation data doesn't need to be gradually done in step by step. The methodology in this research compares the data pattern from the simulation results of the high degree function with the results of interpolation and extrapolation from the results of the IN series simulation. Furthermore, will be carried out comparison simulation analysis of the summation of the function values gradually with the extrapolation function directly using the IN series. The result of comparison simulation analysis point out that the value of the total summation of data between the gradual and the direct summation is the same, so that the direct sum technique using the IN Series is able to make the total sum process more efficient.
\end{abstract}

Keywords: IN series, Newton series, extrapolation, interpolation 


\section{International Journal of Applied Sciences and Smart Technologies}

Volume 2, Issue 1, pages 59-66

p-ISSN 2655-8564, e-ISSN 2685-9432

\section{Introduction}

The IN series, namely Ivan Newton Series (according to HKI EC00201856522), is a further development of the Newton series [1]. A function that is built from a Newton series must have function basis which has a form $\prod_{i=0}^{n}(x-i)$, where the value of $\mathrm{n}$ is a positive integer [2]. If the numbers of the function that has been successfully built by the Newton series are summed gradually, of course there will be inefficient constraints because it will require repetitive summation processes carried out sequentially so that it can take longer than without the repeated summation process. Therefore the sum of extrapolation results can later be obtained in a more efficient way, so a new series has been developed, namely Ivan Newton series or abbreviated as IN series [3]. This IN series is generated from the function basis of multilevel series of $j$ in one degree $\sum_{j=1}^{t}{ }^{u+i-1} j$ where the values of $u, i$, and $t$ are positive integers. Of course if the function data is not summed, so the form of the function basis will be similar to the function basis of the Newton series. Its function base if $u=0$ we have

$$
\frac{1}{(n-1) !} \prod_{i=0}^{n}(x+i)
$$

Because this function base equation has similarities and capabilities similar to the Newton series, which is able to interpolate and extrapolate the data, so this series is named Ivan Newton series.

\section{Basic Theory}

Before discussing the IN series, it will be explained about multilevel series of $j$ in one degree which plays an important role as the function basis of the IN series [4]. The multilevel series of $j$ in one degree is the series of $j$ in one degree which is repeated again in addition, with an initial limit of one [5]. To be clearer, this below is a definition of the notation of the multilevel summation, with $t$ and $u$ is a positive integer, where $t \geq 1$ and $u \geq 0$. 
Volume 2, Issue 1, pages 59-66

p-ISSN 2655-8564, e-ISSN 2685-9432

$$
\begin{aligned}
\sum_{i=1}^{t}{ }^{0} i & \equiv t \\
\sum_{i=1}^{t}{ }^{1} i & \equiv \sum_{i=1}^{t} i \equiv 1+2+3+\ldots . .+t \\
\sum_{i=1}^{t}{ }^{2} i & \equiv \sum_{j}^{t} \sum_{i=1}^{j} i \equiv 1+(1+2)+(1+2+3)+\ldots .+(1+2+3+\ldots .+t)
\end{aligned}
$$

Furthermore, in general it can be obtained [4],

$$
\sum_{i=1}^{t}{ }^{u} i=\left(\begin{array}{l}
t+u \\
u+1
\end{array}\right)
$$

The form of the IN series [3] which uses the function basis of the multilevel series of $j$ in one degree equation (4) is

$$
\begin{aligned}
& \sum_{i=1}^{t}{ }^{u} f(\alpha \cdot i) \cong \sum_{l=0}^{\beta} b_{l} \cdot g(l, u, t) \\
& \cong b_{0} \cdot g(0, u, t)+b_{1} \cdot g(1, u, t)+b_{2} \cdot g(2, u, t)+ \\
& b_{3} \cdot g(3, u, t)+\ldots \ldots \ldots \ldots \ldots \ldots . . .+b_{\beta} \cdot g(\beta, u, t) .
\end{aligned}
$$

where

$$
g(i, u, t)=\sum_{j=1}^{t}{ }^{u+i-1} j=\left(\begin{array}{c}
u+i+t-1 \\
u+i
\end{array}\right)
$$

The smallest function base if the value $i=0$ is

$$
g(0, u, t)=\left(\begin{array}{c}
t+u-1 \\
u
\end{array}\right)
$$

In the formula of the IN series equation (3), the value of the variable $t$ is a positive integer for value $u \geq 1$, but if $u=0$ the the range for the variable value $t$ changes to a real number, the formula is the same as in the Newton series. The formula form of the IN series which the results are not summed with the value $u=0$ and the difference factor between discrete data $\alpha=1$ in the equation (3) is

$$
\begin{aligned}
& \sum_{i=1}^{t}{ }^{0} f(i)=f(t) \cong b_{0}+b_{1} \cdot t+b_{2} \cdot \frac{t \cdot(t+1)}{2 !}+ \\
& b_{3} \cdot \frac{t \cdot(t+1) \cdot(t+2)}{3 !}+\ldots \ldots \ldots \ldots+b_{\beta} \cdot \frac{\prod_{k=0}^{\beta-1}(t+k)}{\beta . !} .
\end{aligned}
$$

or 


\section{International Journal of Applied Sciences and Smart Technologies}

Volume 2, Issue 1, pages 59-66

p-ISSN 2655-8564, e-ISSN 2685-9432

$$
f(t) \cong b_{0}+\sum_{j=1}^{\beta} b_{j} \cdot \frac{\prod_{k=0}^{j-1}(t+k)}{j !}
$$

with the value of $b_{0}=f(0)$.

By using the interpolation method of the IN series, the constants that compose the IN series equation (3) can be generated [6], that is:

$$
b_{0}=f(0), \quad b_{1}=-\left(f(-1)-b_{0}\right)
$$

and

$$
b_{l}=\left(\begin{array}{c}
f(-l)-b_{0}-b_{1} \cdot(-l)-b_{2} \cdot \frac{\prod_{k=0}^{1}(-l+k)}{2 !}-b_{3} \cdot \frac{\prod_{k=0}^{2}(-l+k)}{3 !} \\
\prod_{k=0}^{l-2}(-l+k) \\
\ldots \ldots \ldots \ldots . . .-b_{l-1} \cdot(l-1) !
\end{array}\right) \cdot \frac{l !}{\prod_{k=0}^{l-1}(-l+k)}
$$

or

$$
b_{l}=\left(f(-l)-b_{0}-\sum_{j=1}^{l-1} b_{j} \cdot \frac{\prod_{k=0}^{j-1}(-l+k)}{(j-1) !}\right) \cdot \frac{l . !}{\prod_{k=0}^{l-1}(-l+k)}
$$

where the value range $l$ is positive integer numbers, $l=2,3,4, \ldots$

\section{Results and Discussions}

From equation (9) and (10), an algorithm for interpolation can be made using the IN series. An example of the initial polynomial data that will be used for interpolation is to find the values of constants in the IN series in Table 1 derived from the polynomial function equation (11).

The data in this Table 1 are derived from the polynomial function that will be used for the direct sum extrapolation test in the Table 3, that is:

$$
f(x)=1+x-\frac{x^{2}}{2^{2}}+\frac{x^{4}}{4^{4}}-\frac{x^{6}}{7^{6}}-\frac{x^{8}}{10^{8}}+\frac{x^{10}}{(11.4)^{10}}
$$




\section{International Journal of Applied Sciences and Smart Technologies}

Volume 2, Issue 1, pages 59-66

p-ISSN 2655-8564, e-ISSN 2685-9432

with a range of abscissa from -22 to 22 , a representation of the polynomial function can be described through Figure 1.

Table 1. Interpolation polynomial data in the IN series

\begin{tabular}{cr}
\hline $\boldsymbol{t}$ & $\boldsymbol{f}(\boldsymbol{t})$ \\
\hline 0 & 1 \\
-1 & -0.246 \\
-2 & -1.938 \\
-3 & -3.939 \\
-4 & -6.035 \\
-5 & -7.945 \\
-6 & -9.349 \\
-7 & -9.921 \\
-8 & -9.367 \\
-9 & -7.474 \\
-10 & -4.167 \\
-11 & 0.439 \\
-12 & 5.989 \\
\hline
\end{tabular}

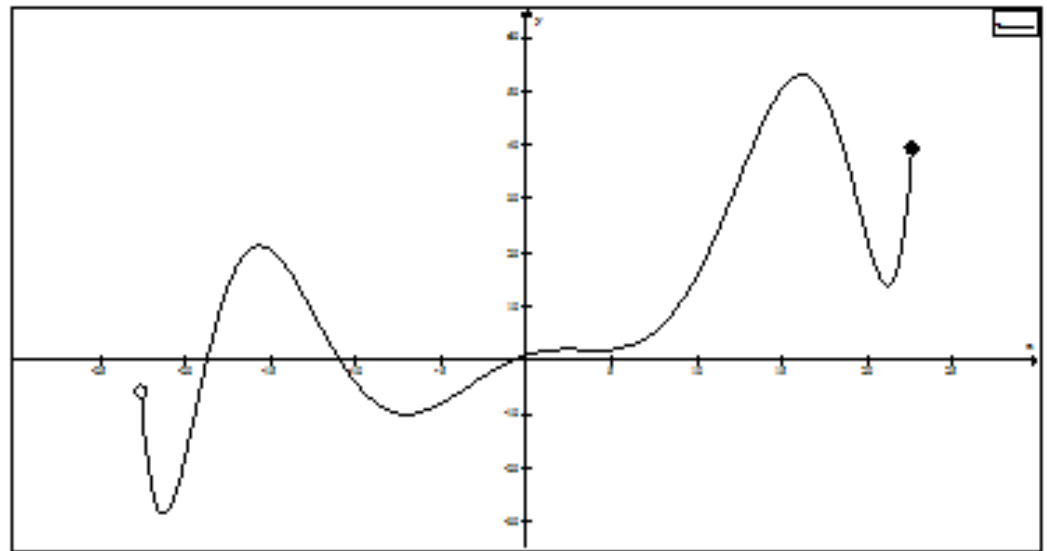

Figure 1. Graph of a polynomial function equation

After using the interpolation formula of the IN series, equation (8) and (9), can be generated the constants in each basis of the IN series function as shown in Table 2 . 


\section{International Journal of Applied Sciences and Smart Technologies}

Volume 2, Issue 1, pages 59-66

p-ISSN 2655-8564, e-ISSN 2685-9432

Table 2. Constant values on the IN series function

\begin{tabular}{cr}
\hline $\boldsymbol{n}$ & $\boldsymbol{b}(\boldsymbol{n})$ \\
\hline 0 & 1 \\
1 & 1.24610226 \\
2 & -0.44584200 \\
3 & -0.13597862 \\
4 & 0.08010405 \\
5 & 0.01642209 \\
6 & -0.00759176 \\
7 & 0.00061180 \\
8 & 0.00041250 \\
9 & -0.00044048 \\
10 & $9.7884 E-05$ \\
11 & $-7.6206 E-13$ \\
12 & $-1.7150 E-12$ \\
\hline
\end{tabular}

Generating of the IN series function can be done after the constant values in Table 2 are obtained. Then the data extrapolation test and summation are carried out, summation in level one directly from the interpolated polynomial function using the EXCEL. The results are shown in Table 3.

Table 3. Comparison test of extrapolation data and direct summation using the IN series

\begin{tabular}{ccccc}
\hline $\boldsymbol{t}$ & $\begin{array}{c}\text { Data from } \\
\text { the actual polynomial } \\
\text { function } \boldsymbol{f}(\boldsymbol{t})\end{array}$ & $\begin{array}{c}\text { Gradual data } \\
\text { summation of } \\
\text { function } \boldsymbol{f}(\boldsymbol{t})\end{array}$ & $\begin{array}{c}\text { Ekstrapolation data } \\
\text { using IN series }\end{array}$ & $\begin{array}{c}\text { Summation of data } \\
\text { directly using IN series }\end{array}$ \\
\hline 1 & 1.753898 & 1.753898 & 1.753898 & 1.753898 \\
2 & 2.061953 & 3.815851 & 2.061953 & 3.815851 \\
3 & 2.060146 & 5.875997 & 2.060146 & 5.875997 \\
4 & 1.964557 & 7.840555 & 1.964557 & 7.840555 \\
5 & 2.054953 & 9.895508 & 2.054953 & 9.895508 \\
6 & 2.650765 & 12.54627 & 2.650765 & 12.54627 \\
7 & 4.078878 & 16.62515 & 4.078878 & 16.62515 \\
8 & 6.633004 & 23.25816 & 6.633004 & 23.25815 \\
9 & 10.52532 & 33.78347 & 10.52532 & 33.78347 \\
10 & 15.83238 & 49.61586 & 15.83238 & 49.61586 \\
11 & 22.43944 & 72.0553 & 22.43944 & 72.0553 \\
12 & 29.98992 & 102.0452 & 29.98992 & 102.0452 \\
13 & 37.85055 & 139.8958 & 37.85054 & 139.8958 \\
14 & 45.10707 & 185.0028 & 45.10706 & 185.0028 \\
15 & 50.61107 & $\mathbf{2 3 5 . 6 1 3 9}$ & 50.61105 & $\mathbf{2 3 5 . 6 1 3 9}$ \\
\hline
\end{tabular}




\section{International Journal of Applied Sciences and Smart Technologies}

Volume 2, Issue 1, pages 59-66

p-ISSN 2655-8564, e-ISSN 2685-9432

After obtaining the extrapolation data, it is necessary to compare the data result with the actual polynomial function, it turns out that from Table 3 the same data results are obtained. Furthermore, it is also necessary to compare the sum results of polynomial function data one by one with the sum results directly using the IN series, it turns out that from Table 3 the same results are also obtained.

\section{Conclusions}

a. Ivan Newton series or IN series is a series formula that is more general than the Newton series because it is able to direct summation of extrapolation data on polynomial functions.

b. The basis of the function that compose the IN series is the multilevel series of $j$ in one degree.

c. Interpolation simulation from IN series can be used to extrapolate data well if the data characteristic is polynomial function.

d. In the future the IN series can be utilized in numerical methods.

\section{Acknowledgements}

This work was supported by the LPPM Atma Jaya Catholic University. The author thanks the reviewers for their suggestions, which have improved the quality of this paper.

\section{References}

[1] I. Newton, "Philosophiae naturalis principia mathematica Book III," London, 1687.

[2] R. W. Hamming, "Numerical methods for scientists and engineering: 2nd," Dover Publication, Inc. New York, 1973.

[3] S. I. Goenawan, "Deret IN (Ivan Newton): formula efisien untuk jumlahan bertingkat data interpolasi atau ekstrapolasi," HKI EC00201856522, 2018.

[4] S. I. Goenawan, "Deret bertingkat berderajat satu dalam teori keteraturan," Metris, 4 (1), 50-56, 2003. 
International Journal of Applied Sciences and Smart Technologies

Volume 2, Issue 1, pages 59-66

p-ISSN 2655-8564, e-ISSN 2685-9432

[5] S. I. Goenawan, "Teori keteraturan,” ATMA nan JAYA, Jakarta, 1998.

[6] S. I. Goenawan, "Deret garis bertingkat dalam teori keteraturan," Metris, 3 (3), $50-57,2002$. 